\title{
Performance of the major semiempirical, ab initio, and density functional theory methods in evaluating isomerization enthalpies for linear to branched heptanes
}

\author{
Sierra Rayne ${ }^{\mathrm{a}, *}$, Kaya Forest ${ }^{\mathrm{b}}$ \\ ${ }^{a}$ Ecologica Research, Penticton, British Columbia V2A 8J3, Canada \\ ${ }^{b}$ Department of Chemistry, Okanagan College, Penticton, British Columbia V2A 8E1, \\ Canada
}

\begin{abstract}
The gas phase standard state $(298.15 \mathrm{~K}, 1 \mathrm{~atm})$ isomerization enthalpy $\left(\Delta_{i s o m} \mathrm{H}_{(g)}^{\circ}\right)$ prediction performance of the major semiempirical, ab initio, and density functional levels of theory was investigated using the linear to branched heptanes. The M062X density functional, MP2 (and higher) levels of Moller-Plesset perturbation theory, and the CBS and Gaussian-n composite methods are best suited for thermodynamic studies of alkane derivative isomerizations expected during the processing of petroleum, biomass, coal, or other fuels. Where large molecular systems prohibit the use of higher levels of theory, the PM6 and PDDG semiempirical methods may offer an appropriate computational cost-accuracy compromise. Non-M062X density functionals are not recommended for theoretical studies of alkane derivative isomerizations.
\end{abstract}

Keywords: Isomerization enthalpies, Heptanes, Theoretical methods, Benchmarking

\section{Introduction}

During petroleum cracking, hydrocracking, and catalytic reforming, isomerization reactions occur that convert linear alkanes into branched chain, cyclic, and aromatic derivatives.[1] Analogous isomerizations occur during

\footnotetext{
*Corresponding author. Tel.: $\quad+1250487$ 0166. E-mail address: rayne.sierra@gmail.com (S. Rayne).
} 
the thermal processing of coal and biomass into liquid and gaseous fuels. [24] Computational methods are widely employed to study the corresponding reaction thermodynamics and kinetics, often to acquire additional supporting data, because the systems are difficult and expensive to study experimentally, or because the theoretical approaches are being used to model proposed fuel processing technologies. In many cases, particularly with heavy petroleum feeds, biomass, and coal, the molecules under study are too computationally expensive for accurate high level Complete Basis Set (CBS), [5, 6] Gaussian$\mathrm{n},[7,8]$ or $\mathrm{W} 1 / \mathrm{W} 2[9,10]$ methods to be applied, and less expensive density functional theory (DFT) or semiempirical approaches need to be used.

Because of rapid advances in computing power, the number of research groups working in the field, and academic and industrial demand for theoretical studies, the past two decades have seen a large increase in the number of density functionals widely available in commercial software packages, as well as the evolution of new semiempirical, CBS, and Gaussian-n methods. However, an emerging awareness of the opportunities and limitations of these methods recognizes that not all model chemistries offer equal, or satisfactory, accuracy for a particular theoretical task.[11-19] The problems are especially acute for isomerization enthalpies of compounds relevant to the fuel processing industry, where some DFT and semiempirical methods exhibit severe errors.[20-23] In previous work, we demonstrated that the alkane derivative branching errors in gas phase standard state $(298.15 \mathrm{~K}, 1 \mathrm{~atm})$ isomerization enthalpies $\left(\Delta_{\text {isom }} \mathrm{H}_{(g)}^{\circ}\right)$ for the popular B3LYP density functional do not become clear until chain lengths of 5 to 6 carbons and higher.[24] In contrast, newer density functionals such as the M062X model chemistry, recently developed semiempirical methods (e.g., PDDG and PM6), and the CBS and Gaussian-n level composite methods do not exhibit an abrupt increase in alkane derivative $\Delta_{i s o m} \mathrm{H}_{(g)}^{\circ}$ errors over this homolog range.[25]

Consequently, comprehensive benchmarking studies for alkane derivative branching $\Delta_{i s o m} \mathrm{H}_{(g)}^{\circ}$ across a broad number of theoretical methods are most readily conducted on the heptanes. A sufficient number $(n=9$; Fig. 1) of straight chain and branched heptane isomers are available for error analyses, the individual compounds incur only modest computational expense even using CBS and Gaussian-n composite methods, the number of isomers in the $\mathrm{C}_{7}$ alkane homolog is not excessively large such that an investigation of the major semiempirical, ab initio, and density functional theory model chemistries and various basis sets would become computationally intractable, 
and branching errors are known to manifest themselves prior to reaching this homolog group. To help ground future theoretical studies on fuel processing, and guide efforts in assessing the accuracy of historical investigations, the current work examines the linear to branched heptane $\Delta_{i s o m} \mathrm{H}_{(g)}^{\circ}$ prediction capability of the major semiempirical, ab initio, and DFT levels of theory.

\section{Material and Methods}

Calculations were conducted using Gaussian 09 [26] on the Western Canada Research Grid (WestGrid; project 100185 [K. Forest]) and the Shared Hierarchical Academic Research Computing Network (SHARCNET; project sn4612 [K. Forest]), both within the umbrella of Compute/Calcul Canada. All calculations used the same gas phase starting geometries obtained with the PM6 semiempirical method [27] as implemented in MOPAC 2009 (http: //www.openmopac.net/; v. 9.281). Semiempirical calculations used the AM1,[28, 29] PM3/PM3MM, [30, 31] PM6,[27] and PDDG [13, 19, 32] methods as reimplemented [33] in Gaussian 09.

Density functional theory (DFT) calculations used the B3LYP [34-36] hybrid density functional with the STO-3G, [37, 38] 3-21+G, [39-41] 6-21G**, [39, 40] 4-31G**, [42-45] 6-31++G(d,p) and 6-311++G(d,p),[42-47] D95++(d,p) and D95V++(d,p),[48] SHC*, [48, 49] CEP-4G*, CEP-31G*, and CEP-121G*, [50] LanL2MB,[37, 38, 51, 52] LanL2DZ, [48, 51, 52] SDDAll,[48, 53] augcc-pVDZ and aug-cc-pVTZ,[54-58] SV, SVP, and TZVP,[59, 60] QZVP,[61] MIDI!,[62] EPR-III, MTSmall,[9] DGDZVP, DGDZVP2, and DGTZVP, [63, 64] and CBSB7++ [65] basis sets, the $\mathrm{HCTH} / 407$ [66-68] standalone density functional, and the B98,[69, 70] mPW1LYP,[35, 36, 71] and M062X [72] hybrid density functionals, with the CEP-4G*,[50] 6-311++G(d,p),[42-47] and aug-cc-pVDZ and aug-cc-pVTZ [54-58] basis sets, and the B3P86,[34, 73] B3PW91,[34, 74-76] B1B95,[77, 78] mPW1PW91,[71, 74-76] mPW1PBE,[71, 79, 80] mPW3PBE,[71, 79, 80] B971,[66] B972,[81] PBE1PBE,[79, 80, 82] B1LYP, [35, 36, 77] O3LYP, [35, 36, 83] BMK,[84] M06,[72] M06HF,[85, 86] $\tau$ HCTHhyb, [68] HSEh1PBE and HSE2PBE, [79, 80, 87-93] PBEh1PBE,[79, 80, 94] HFS, [95, 96] HFB, [77] X3LYP, [35, 36, 97] and TPSSh [98] hybrid density functionals, the VSXC,[99] HCTH/93, HCTH/147, and $\mathrm{HCTH} / 407$, [6668] $\tau \mathrm{HCTH},[68], \mathrm{M} 06 \mathrm{~L},[100]$ and B97D [101] standalone density functionals, the BHandH and BHandHLYP half-and-half density functionals, and the LCwPBE,[102-105] CAM-B3LYP, [35, 36, 106] wB97XD,[107] wB97X,[108] and 
wB97 [108] long range corrected density functionals with the CEP-4G*, [50] 6-311++G(d,p),[42-47] and aug-cc-pVDZ [54-58] basis sets.

$\mathrm{Ab}$ initio Hartree-Fock (HF) calculations were conducted using the CEP$4 \mathrm{G}^{*},[50]$ 6-311++G(d,p),[42-47] and aug-cc-pVDZ and aug-cc-pVTZ,[54-58] basis sets. Second order Moller-Plesset perturbation theory (MP2) [109112] calculations used the CEP-4G*,[50] 6-311++G(d,p),[42-47] and aug-ccpVDZ [54-58] basis sets. Complete Basis Set (CBS) [5, 6, 113-118] calculations used the CBS-4M,[6, 118] CBS-Q//B3,[5, 6] and CBS-APNO [118] methods. Gaussian-n calculations used the Gaussian-1 (G1),[119, 120] Gaussian2 (G2),[121] G2MP2,[122] Gaussian-3 (G3),[123] G3MP2,[124] G3B3,[125] G3MP2B3,[125] G4,[7] and G4MP2 [8] methods.

All optimized structures were confirmed as true minima by vibrational analysis at the same level. Gas phase standard state (1 atm, $298.15 \mathrm{~K}$ ) isomerization enthalpies $\left(\Delta_{i s o m} \mathrm{H}_{(g)}^{\circ}\right)$ include zero point and thermal corrections. Only the lowest energy conformation of each molecule was considered for $\Delta_{i s o m} \mathrm{H}_{(g)}^{\circ}$ calculations. The following gas phase standard state (1 atm, $298.15 \mathrm{~K}$ ) experimental enthalpies of formation $\Delta_{f} \mathrm{H}_{(g)}^{\circ}$ were obtained from ref. [126] and used to calculate corresponding $\Delta_{i s o m} \mathrm{H}_{(g)}^{\circ}$ : n-heptane (1), $44.8 \mathrm{kcal} / \mathrm{mol}$; 2-methylhexane (2), -46.5 kcal/mol; 3-methylhexane (3), -45.7 $\mathrm{kcal} / \mathrm{mol} ; 2,2$ '-dimethylpentane (4), -49.2 kcal/mol; 2,3-dimethylpentane (5), -47.5 kcal $/ \mathrm{mol} ; 2,4$-dimethylpentane (6), -48.2 kcal/mol; 3,3'-dimethylpentane (7), -48.0 kcal/mol; 3-ethylpentane (8), $-45.3 \mathrm{kcal} / \mathrm{mol}$; and 2,2',3-trimethylbutane $(\mathbf{9}),-48.9 \mathrm{kcal} / \mathrm{mol}$.

Bond [18] has recently reanalyzed the $\Delta_{f} \mathrm{H}_{(g)}^{\circ}$ of the heptanes (as part of a larger study on computational hydrocarbon thermochemistry) and put forward the following high level computationally 'corrected' $\Delta_{f} \mathrm{H}_{(g)}^{\circ}: \mathbf{1},-44.7$ $\mathrm{kcal} / \mathrm{mol} ; \mathbf{2},-46.3 \mathrm{kcal} / \mathrm{mol} ; \mathbf{3},-45.7 \mathrm{kcal} / \mathrm{mol} ; \mathbf{4},-49.2 \mathrm{kcal} / \mathrm{mol} ; \mathbf{5},-46.5$ $\mathrm{kcal} / \mathrm{mol} ; \mathbf{6},-48.3 \mathrm{kcal} / \mathrm{mol} ; \mathbf{7},-47.6 \mathrm{kcal} / \mathrm{mol} ; \mathbf{8},-45.0 \mathrm{kcal} / \mathrm{mol}$; and 9, $-49.0 \mathrm{kcal} / \mathrm{mol}$. The mean absolute deviation between the CRC [126] and Bond 'corrected' [18] $\Delta_{f} \mathrm{H}_{(g)}^{\circ}$ for these nine heptane isomers is $0.3 \mathrm{kcal} / \mathrm{mol}$, with a maximum deviation of $1.0 \mathrm{kcal} / \mathrm{mol}$, resulting in similar mean absolute and maximum deviations between the corresponding linear to branched experimental $\Delta_{\text {isom }} \mathrm{H}_{(g)}^{\circ}$. With the various computational methods employed herein, we found that the use of the CRC [126] or Bond 'corrected' [18] $\Delta_{i s o m} \mathrm{H}_{(g)}^{\circ}$ resulted in mean unsigned errors that did not differ by more than $\pm 0.2 \mathrm{kcal} / \mathrm{mol}$ from each other. As a result, we chose to report the calculated $\Delta_{i s o m} \mathrm{H}_{(g)}^{\circ}$ errors relative to the well known CRC [126] $\Delta_{\text {isom }} \mathrm{H}_{(g)}^{\circ}$ experimental 
dataset.

\section{Results and Discussion}

Our $\Delta_{i s o m} \mathrm{H}_{(g)}^{\circ}$ theoretical studies on the heptanes began with an investigation into the predictive performance of the B3LYP functional with levels of the major basis sets available in Gaussian 09. For the majority of basis sets, the B3LYP functional displays a linear to branched heptane $\Delta_{i s o m} \mathrm{H}_{(g)}^{\circ}$ mean unsigned error (MUE) between 4 and $5 \mathrm{kcal} / \mathrm{mol}$ (Table 1). The $3-21+\mathrm{G}$ $(2.1 \mathrm{kcal} / \mathrm{mol}), \mathrm{SHC}^{*}(3.9 \mathrm{kcal} / \mathrm{mol}), \mathrm{CEP}-31 \mathrm{G}^{*}(3.6 \mathrm{kcal} / \mathrm{mol}), \mathrm{LanL} 2 \mathrm{DZ}$ (3.9 kcal/mol), and MIDI! $(2.3 \mathrm{kcal} / \mathrm{mol})$ basis sets have lower MUEs, but still beyond chemical accuracy $(\leq 1 \mathrm{kcal} / \mathrm{mol})$. Only the low-level CEP-4G* $(\mathrm{MUE}=0.9 \mathrm{kcal} / \mathrm{mol})$ achieves heptane $\Delta_{i s o m} \mathrm{H}_{(g)}^{\circ}$ chemical accuracy with the B3LYP functional.

Using the CEP-4G* basis set, as well as the popular $6-311++\mathrm{G}(\mathrm{d}, \mathrm{p})$ Pople-type and aug-cc-pVDZ Dunning-type basis sets, heptane $\Delta_{\text {isom }} \mathrm{H}_{(g)}^{\circ}$ were calculated using the Hartree-Fock and second-order Moller-Plesset perturbation theory (MP2) model chemistries, as well as forms of the major hybrid, standalone, half-and-half, and long range corrected density functionals in Gaussian 09. With the exception of the M06 (M06, M06HF, M062X, and M06L) and B97 (B97D, wB97, wB97X, and wB97XD) families of density functionals, as well as the HFS, VSXC, BHandH, and MP2 methods, all other model chemistries exhibited higher $\Delta_{\text {isom }} \mathrm{H}_{(g)}^{\circ}$ MUEs with increasing basis set size (Table 2). Thus, the majority of model chemistries obtain a more correct answer for an incorrect reason (i.e., lower $\Delta_{i s o m} \mathrm{H}_{(g)}^{\circ}$ MUEs with less complete basis sets). The lower errors observed with the relatively incomplete CEP$4 \mathrm{G}^{*}$ basis set (relative to the $6-311++\mathrm{G}(\mathrm{d}, \mathrm{p})$ and aug-cc-pVDZ basis sets) are particularly evident for hybrid density functionals employing the -LYP correlation functional of Lee, Yang, and Parr (e.g., B3LYP [0.9], X3LYP [1.1], B1LYP [0.8], O3LYP [0.7], mPW1LYP [1.1], BHandHLYP [1.5], and CAM-B3LYP [1.6]; MUEs using the CEP-4G* basis set in $\mathrm{kcal} / \mathrm{mol}$ given in brackets). Only the M06 and B97 DFT families and the HFS, VSXC, $\mathrm{BHandH}$, and MP2 methods achieve a more correct answer for the correct reason (i.e., reduction in $\Delta_{i s o m} \mathrm{H}_{(g)}^{\circ}$ MUEs with more complete basis sets). Even with the error reduction (MUEs of 14.1, 10.1, and $10.0 \mathrm{kcal} / \mathrm{mol}$ using the CEP-4G*, $6-311++\mathrm{G}(\mathrm{d}, \mathrm{p})$, and aug-cc-pVDZ basis sets, respectively) due to use of more complete basis sets, the VSXC standalone density func- 
tional is generally not suited for isomerization enthalpy analyses of alkanes due to the large remaining errors irrespective of basis set size.

For the M062X functional, there is a notable difference in the $\Delta_{i s o m} \mathrm{H}_{(g)}^{\circ}$ errors between the $6-311++\mathrm{G}(\mathrm{d}, \mathrm{p})(\mathrm{MUE}=0.8 \mathrm{kcal} / \mathrm{mol})$ and aug-cc-pVDZ $(\mathrm{MUE}=3.6 \mathrm{kcal} / \mathrm{mol}$ ) basis sets, a divergence that is not evident in other members of the M06 family. When the more complete aug-cc-pVTZ basis set is used, the M062X function recovers its predictive accuracy $\left(\Delta_{i s o m} \mathrm{H}_{(g)}^{\circ}\right.$ MUE [RMSE] (MSE) of 0.9 [1.2] (0.8) kcal/mol). For other representative model chemistries, there is little difference between their $6-311++\mathrm{G}(\mathrm{d}, \mathrm{p})$ and aug-cc-pVDZ $\Delta_{i s o m} \mathrm{H}_{(g)}^{\circ}$ errors and the following errors obtained with the aug-cc-pVTZ basis set (values presented as MUE [RMSE] (MSE) in units of kcal/mol): HF/aug-cc-pVTZ, 6.2 [6.6] (6.2); B3LYP/aug-cc-pVTZ, 4.8 [5.1] (4.8); HCTH/407/aug-cc-pVTZ, 6.2 [6.6] (6.2); B98/aug-cc-pVTZ, 4.3 [4.6] (4.3); and mPW1LYP/aug-cc-pVTZ, 4.5 [4.8] (4.5). Calculations at the MP2/aug-cc-pVTZ level of theory were sufficiently expensive that they were not completed for comparison with the MP2/6-311++G(d,p) and MP2/augcc-pVDZ results given in Table 2 .

Among the low (semiempirical methods) and high (composite methods) computational expense end members, all Gaussian-n methods (G1, G2, G2MP2, G3, G3MP2, G3B3, G3MP2B3, G4, and G4MP2) and the CBS-Q//B3 method achieve chemically accurate heptane $\Delta_{i s o m} \mathrm{H}_{(g)}^{\circ}$ MUEs of 0.8 to 0.9 $\mathrm{kcal} / \mathrm{mol}$ (Table 3). The less expensive CBS-4M composite method has a slightly higher MUE of $1.2 \mathrm{kcal} / \mathrm{mol}$, and the PM6 and PDDG semiempirical methods achieve near chemical accuracy (MUEs of 1.3 and $1.1 \mathrm{kcal} / \mathrm{mol}$, respectively). The legacy AM1 semiempirical method displays gross isomerization errors, resulting in a MUE of $8.8 \mathrm{kcal} / \mathrm{mol}$, while the PM3/PM3MM methods each have MUEs of $3.9 \mathrm{kcal} / \mathrm{mol}$ that are comparable to most DFT functionals using the $6-311++\mathrm{G}(\mathrm{d}, \mathrm{p})$ and aug-cc-pVDZ basis sets. 2,2,3Trimethylbutane could not be converged using a tight convergence criterion with the CBS-APNO method, precluding a complete comparative error analysis with the other levels of theory. However, for the linear to branched $\Delta_{\text {isom }} \mathrm{H}_{(g)}^{\circ}$ of the other 8 heptane isomers (i.e., 7 isomerization reactions), the CBS-APNO method achieved $\Delta_{i s o m} \mathrm{H}_{(g)}^{\circ}$ errors within $\pm 0.2 \mathrm{kcal} / \mathrm{mol}$ of the CBS-4M method and within $\pm 0.4 \mathrm{kcal} / \mathrm{mol}$ of the $\mathrm{CBS}-\mathrm{Q} / / \mathrm{B} 3$ method, yielding MUE [RMSE] (MSE) of 1.2 [1.5] (1.2) kcal/mol that are equivalent to that of the CBS-4M method. 


\section{Conclusions}

A comprehensive survey of heptane $\Delta_{\text {isom }} \mathrm{H}_{(g)}^{\circ}$ predicton capability by the major semiempirical, ab initio, and DFT model chemistries indicates the M062X, MP2 (and higher orders of Moller-Plesset perturbation theory), CBS, and Gaussian-n methods are best suited for thermochemical studies of alkane derivative isomerizations expected during the processing of petroleum, biomass, coal, or other fuels. For larger molecular systems, the reasonable performance of the PM6 and PDDG semiempirical methods may be an appropriate cost-accuracy compromise. For systems that are too large for composite methods - but still tractable at DFT levels of theory - the M062X density functional with a modest basis set size $(6-311++\mathrm{G}(\mathrm{d}, \mathrm{p})$ provides near CBS/Gaussian-n level accuracy at much lower computational cost. Due to their less than chemical accuracy, the use of non-M062X density functionals for studies into the thermodynamics of alkane isomerizations is not recommended.

\section{Acknowledgments}

This work was made possible by the facilities of the Western Canada Research Grid (WestGrid:www.westgrid.ca; project 100185), the Shared Hierarchical Academic Research Computing Network (SHARCNET:www.sharcnet.ca; project sn4612), and Compute/Calcul Canada.

\section{References}

[1] G. Olah, A. Molnar, Hydrocarbon Chemistry, Wiley: New York, NY, USA, 2003.

[2] D. Whitehurst, T. Mitchell, M. Farcasiu, Coal Liquefaction: The Chemistry and Technology of Thermal Processes, Academic Press: New York, NY, USA, 1980.

[3] L. Vernon, Fuel 59 (1980) 102-106.

[4] J. Lange, Biofuels Bioproducts Biorefining 1 (2007) 39-48.

[5] J. Montgomery, M. Frisch, J. Ochterski, G. Petersson, J. Chem. Phys. 110 (1999) 2822-2827. 
[6] J. Montgomery, M. Frisch, J. Ochterski, G. Petersson, J. Chem. Phys. 112 (2000) 6532-6542.

[7] L. Curtiss, P. Redfern, K. Raghavachari, J. Chem. Phys. 126 (2007) 084108 .

[8] L. Curtiss, P. Redfern, K. Raghavachari, J. Chem. Phys. 127 (2007) 124105 .

[9] J. Martin, G. de Oliveira, J. Chem. Phys. 111 (1999) 1843-1856.

[10] S. Parthiban, J. Martin, J. Chem. Phys. 114 (2001) 6014-6029.

[11] M. Saeys, M. Reyniers, G. Marin, V. Van Speybroeck, M. Waroquier, J. Phys. Chem. A 107 (2003) 9147-9159.

[12] C. Check, T. Gilbert, J. Org. Chem. 70 (2005) 9828-9834.

[13] K. W. Sattelmeyer, J. Tirado-Rives, W. L. Jorgensen, J. Phys. Chem. A 110 (2006) 13551-13559.

[14] M. Wodrich, C. Corminboeuf, P. Schleyer, Org. Lett. 8 (2006) 36313634.

[15] M. Wodrich, C. Corminboeuf, P. Schreiner, A. Fokin, P. Schleyer, Org. Lett. 9 (2007) 1851-1854.

[16] D. Bond, J. Org. Chem. 72 (2007) 5555-5566.

[17] D. Bond, J. Org. Chem. 72 (2007) 7313-7328.

[18] D. Bond, J. Phys. Chem. A 112 (2008) 1656-1660.

[19] J. Tirado-Rives, W. L. Jorgensen, J. Chem. Theory Comput. 4 (2008) 297-306.

[20] S. Grimme, Angew. Chem. Int. Ed. 45 (2006) 4460-4464.

[21] P. Schreiner, A. Fokin, R. Pascal, A. de Meijere, Org. Lett. 8 (2006) 3635-3638.

[22] S. Grimme, M. Steinmetz, M. Korth, J. Chem. Theory Comput. 3 (2007) 42-45. 
[23] S. Grimme, M. Steinmetz, M. Korth, J. Org. Chem. 72 (2007) 21182126.

[24] S. Rayne, K. Forest, J. Mol. Struct. THEOCHEM 941 (2010) 107-118.

[25] S. Rayne, K. Forest, J. Mol. Struct. THEOCHEM 948 (2010) 102-107.

[26] M. J. Frisch, G. W. Trucks, H. B. Schlegel, G. E. Scuseria, M. A. Robb, J. R. Cheeseman, G. Scalmani, V. Barone, B. Mennucci, G. A. Petersson, H. Nakatsuji, M. Caricato, X. Li, H. P. Hratchian, A. F. Izmaylov, J. Bloino, G. Zheng, J. L. Sonnenberg, M. Hada, M. Ehara, K. Toyota, R. Fukuda, J. Hasegawa, M. Ishida, T. Nakajima, Y. Honda, O. Kitao, H. Nakai, T. Vreven, J. A. Montgomery, J. E. Peralta, F. Ogliaro, M. Bearpark, J. J. Heyd, E. Brothers, K. N. Kudin, V. N. Staroverov, R. Kobayashi, J. Normand, K. Raghavachari, A. Rendell, J. C. Burant, S. S. Iyengar, J. Tomasi, Gaussian 09, Gaussian, Inc.: Wallingford, CT, U.S.A., 2009.

[27] J. Stewart, J. Mol. Model. 13 (2007) 1173-1213.

[28] M. J. S. Dewar, W. Thiel, J. Am. Chem. Soc. 99 (1977) 4899-4907.

[29] M. J. S. Dewar, E. G. Zoebisch, E. F. Healy, J. J. P. Stewart, J. Am. Chem. Soc. 107 (1985) 3902-3909.

[30] J. Stewart, J. Comp. Chem. 10 (1989) 221-264.

[31] J. Stewart, J. Comp. Chem. 10 (1989) 209-220.

[32] M. P. Repasky, J. Chandrasekhar, W. L. Jorgensen, J. Comp. Chem. 23 (2002) 1601-1622.

[33] W. Thiel, A. A. Voityuk, Theor. Chem. Acc. 81 (1992) 391-404.

[34] A. D. Becke, J. Chem. Phys. 98 (1993) 5648-5652.

[35] C. Lee, W. Yang, R. G. Parr, Phys. Rev. B 37 (1988) 785-789.

[36] B. Miehlich, A. Savin, H. Stoll, H. Preuss, Chem. Phys. Lett. 157 (1989) 200-206.

[37] W. J. Hehre, R. F. Stewart, J. A. Pople, J. Chem. Phys. 51 (1969) 2657-2664. 
[38] J. B. Collins, P. V. R. Schleyer, J. S. Binkley, J. A. Pople, J. Chem. Phys. 64 (1976) 5142-5151.

[39] J. S. Binkley, J. A. Pople, W. J. Hehre, J. Am. Chem. Soc. 102 (1980) 939-947.

[40] M. S. Gordon, J. S. Binkley, J. A. Pople, W. J. Pietro, W. J. Hehre, J. Am. Chem. Soc. 104 (1982) 2797-2803.

[41] W. J. Pietro, M. M. Francl, W. J. Hehre, D. J. DeFrees, J. A. Pople, J. S. Binkley, J. Am. Chem. Soc. 104 (1982) 5039-5048.

[42] R. Ditchfield, W. J. Hehre, J. A. Pople, J. Chem. Phys. 54 (1971) $724-728$.

[43] W. J. Hehre, R. Ditchfield, J. A. Pople, J. Chem. Phys. 56 (1972) $2257-2261$.

[44] P. C. Hariharan, J. A. Pople, Mol. Phys. 27 (1974) 209-209.

[45] M. S. Gordon, Chem. Phys. Lett. 76 (1980) 163-168.

[46] P. C. Hariharan, J. A. Pople, Theor. Chem. Acc. 28 (1973) 213-222.

[47] M. M. Francl, J. Chem. Phys. 77 (1982) 3654-3654.

[48] T. H. Dunning, P. J. Hay, Modern Theoretical Chemistry, Plenum: New York, NY, USA, pp. 1-28.

[49] A. K. Rappe, T. A. Smedley, W. A. Goddard, J. Phys. Chem. 85 (1981) 1662-1666.

[50] W. J. Stevens, H. Basch, M. Krauss, J. Chem. Phys. 81 (1984) 60266033 .

[51] W. R. Wadt, P. J. Hay, J. Chem. Phys. 82 (1985) 284-298.

[52] P. J. Hay, W. R. Wadt, J. Chem. Phys. 82 (1985) 299-310.

[53] G. Igel-Mann, H. Stoll, H. Preuss, Mol. Phys. 65 (1988) 1321-1328.

[54] T. H. Dunning, J. Chem. Phys. 90 (1989) 1007-1023. 
[55] R. A. Kendall, T. H. Dunning, R. J. Harrison, J. Chem. Phys. 96 (1992) 6796-6806.

[56] D. Woon, T. Dunning, J. Chem. Phys. 98 (1993) 1358-1371.

[57] A. K. Wilson, T. van Mourik, T. H. Dunning, J. Mol. Struct. THEOCHEM 388 (1996) 339-349.

[58] E. R. Davidson, Chem. Phys. Lett. 260 (1996) 514-518.

[59] A. Schafer, H. Horn, R. Ahlrichs, J. Chem. Phys. 97 (1992) 2571-2577.

[60] A. Schafer, C. Huber, R. Ahlrichs, J. Chem. Phys. 100 (1994) 58295835 .

[61] F. Weigend, R. Ahlrichs, Phys. Chem. Chem. Phys 7 (2005) 3297-3305.

[62] R. E. Easton, D. J. Giesen, A. Welch, C. J. Cramer, D. G. Truhlar, Theor. Chem. Acc. 93 (1996) 281-301.

[63] N. Godbout, D. R. Salahub, J. Andzelm, E. Wimmer, Can. J. Chem. 70 (1992) 560-571.

[64] C. Sosa, J. Andzelm, B. C. Elkin, E. Wimmer, K. D. Dobbs, D. A. Dixon, J. Phys. Chem. 96 (1992) 6630-6636.

[65] J. A. Montgomery, M. J. Frisch, J. W. Ochterski, G. A. Petersson, J. Chem. Phys. 110 (1999) 2822-2827.

[66] F. A. Hamprecht, A. J. Cohen, D. J. Tozer, N. C. Handy, J. Chem. Phys. 109 (1998) 6264-6271.

[67] A. D. Boese, N. C. Handy, J. Chem. Phys. 114 (2001) 5497-5503.

[68] A. D. Boese, N. C. Handy, J. Chem. Phys. 116 (2002) 9559-9569.

[69] A. D. Becke, J. Chem. Phys. 107 (1997) 8554-8560.

[70] H. L. Schmider, A. D. Becke, J. Chem. Phys. 108 (1998) 9624-9631.

[71] C. Adamo, V. Barone, J. Chem. Phys. 108 (1998) 664-675.

[72] Y. Zhao, D. Truhlar, Theor. Chem. Acc. 120 (2008) 215-241. 
[73] J. P. Perdew, Phys. Rev. B 33 (1986) 8822-8822.

[74] J. P. Perdew, J. A. Chevary, S. H. Vosko, K. A. Jackson, M. R. Pederson, D. J. Singh, C. Fiolhais, Phys. Rev. B 46 (1992) 6671-6671.

[75] J. P. Perdew, J. A. Chevary, S. H. Vosko, K. A. Jackson, M. R. Pederson, D. J. Singh, C. Fiolhais, Phys. Rev. B 48 (1993) 4978-4978.

[76] J. P. Perdew, K. Burke, Y. Wang, Phys. Rev. B 54 (1996) 16533-16533.

[77] A. D. Becke, Phys. Rev. A 38 (1988) 3098-3098.

[78] A. D. Becke, J. Chem. Phys. 104 (1996) 1040-1046.

[79] J. Perdew, K. Burke, M. Ernzerhof, Phys. Rev. Lett. 77 (1996) 38653868.

[80] J. Perdew, K. Burke, M. Ernzerhof, Phys. Rev. Lett. 78 (1997) 1396.

[81] P. Wilson, T. Bradley, D. Tozer, J. Chem. Phys. 115 (2001) 9233-9242.

[82] C. Adamo, V. Barone, J. Chem. Phys. 110 (1999) 6158-6169.

[83] A. Cohen, N. Handy, Mol. Phys. 99 (2001) 607-615.

[84] A. Boese, J. Martin, J. Chem. Phys. 121 (2004) 3405-3416.

[85] Y. Zhao, D. Truhlar, J. Phys. Chem. 110 (2006) 5121-5129.

[86] Y. Zhao, D. Truhlar, J. Phys. Chem. A 110 (2006) 13126-13130.

[87] J. Heyd, G. Scuseria, J. Chem. Phys. 121 (2004) 1187-1192.

[88] J. Heyd, G. Scuseria, J. Chem. Phys. 120 (2004) 7274.

[89] J. Heyd, J. Peralta, G. Scuseria, R. Martin, J. Chem. Phys. 123 (2005) 174101.

[90] J. Heyd, G. Scuseria, M. Ernzerhof, J. Chem. Phys. 124 (2006) 219906.

[91] A. Izmaylov, G. Scuseria, M. Frisch, J. Chem. Phys. 125 (2006) 104103.

[92] A. Krukau, O. Vydrov, A. Izmaylov, G. Scuseria, J. Chem. Phys. 125 (2006) 224106. 
[93] T. Henderson, A. Izmaylov, G. Scalmani, G. Scuseria, J. Chem. Phys. 131 (2009) 044108.

[94] M. Ernzerhof, J. Perdew, J. Chem. Phys. 109 (1998) 3313.

[95] P. Hohenberg, W. Kohn, Phys. Rev. 136 (1964) B864-B871.

[96] W. Kohn, L. Sham, Phys. Rev. 140 (1965) A1133-A1138.

[97] X. Xu, W. Goddard, Proc. Natl. Acad. Sci. USA 101 (2004) 2673-2677.

[98] J. Tao, J. Perdew, V. Staroverov, G. Scuseria, Phys. Rev. Lett. 91 (2003) 146401.

[99] T. Van Voorhis, G. E. Scuseria, J. Chem. Phys. 109 (1998) 400-410.

[100] Y. Zhao, D. G. Truhlar, J. Chem. Phys. 125 (2006) 194101-194118.

[101] S. Grimme, J. Comp. Chem. 27 (2006) 1787-1799.

[102] Y. Tawada, T. Tsuneda, S. Yanagisawa, T. Yanai, K. Hirao, J. Chem. Phys. 120 (2004) 8425-8433.

[103] O. A. Vydrov, J. Heyd, A. V. Krukau, G. E. Scuseria, J. Chem. Phys 125 (2006) 74106.

[104] O. A. Vydrov, G. E. Scuseria, J. Chem. Phys. 125 (2006) 234109.

[105] O. A. Vydrov, G. E. Scuseria, J. P. Perdew, J. Chem. Phys. 126 (2007) 154109.

[106] T. Yanai, D. P. Tew, N. C. Handy, Chem. Phys. Lett. 393 (2004) 51-57.

[107] J. D. Chai, M. Head-Gordon, Phys. Chem. Chem. Phys. 10 (2008) 6615-6620.

[108] J. D. Chai, M. Head-Gordon, J. Chem. Phys. 128 (2008) 84106-84115.

[109] M. Head-Gordon, J. A. Pople, M. J. Frisch, Chem. Phys. Lett. 153 (1988) 503-506.

[110] S. Saebo, J. Almlof, Chem. Phys. Lett. 154 (1989) 83-89. 
[111] M. Frisch, M. Head-Gordon, J. Pople, Chem. Phys. Lett. 166 (1990) $275-280$.

[112] M. Frisch, M. Head-Gordon, J. Pople, Chem. Phys. Lett. 166 (1990) 281-289.

[113] M. Nyden, G. Petersson, J. Chem. Phys. 75 (1981) 1843-1862.

[114] G. Petersson, A. Bennett, T. Tensfeldt, M. Al-Laham, W. Shirley, J. Mantzaris, J. Chem. Phys. 89 (1988) 2193-2218.

[115] G. Petersson, M. Al-Laham, J. Chem. Phys. 94 (1991) 6081-6090.

[116] G. Petersson, T. Tensfeldt, J. Montgomery, J. Chem. Phys. 94 (1991) 6091-6101.

[117] J. Montgomery, J. Ochterski, G. Petersson, J. Chem. Phys. 101 (1994) 5900-5909.

[118] J. Ochterski, G. Petersson, J. Montgomery, J. Chem. Phys. 104 (1996) 2598-2619.

[119] J. Pople, M. Head-Gordon, D. Fox, K. Raghavachari, L. Curtiss, J. Chem. Phys. 90 (1989) 5622-5629.

[120] L. Curtiss, C. Jones, G. Trucks, K. Raghavachari, J. Pople, J. Chem. Phys. 93 (1990) 2537-2545.

[121] L. Curtiss, K. Raghavachari, G. Trucks, J. Pople, J. Chem. Phys. 94 (1991) 7221-7230.

[122] L. Curtiss, K. Raghavachari, J. Pople, J. Chem. Phys. 98 (1993) 12931298.

[123] L. Curtiss, K. Raghavachari, P. Redfern, V. Rassolov, J. Pople, J. Chem. Phys. 109 (1998) 7764-7776.

[124] L. Curtiss, P. Redfern, K. Raghavachari, V. Rassolov, J. Pople, J. Chem. Phys. 110 (1999) 4703-4709.

[125] A. Baboul, L. Curtiss, P. Redfern, K. Raghavachari, J. Chem. Phys. 110 (1999) 7650-7657. 
[126] D. R. Lide, CRC Handbook of Chemistry and Physics, Taylor \& Francis: Boca Raton, FL, U.S.A., 2008. 


\section{Figures}

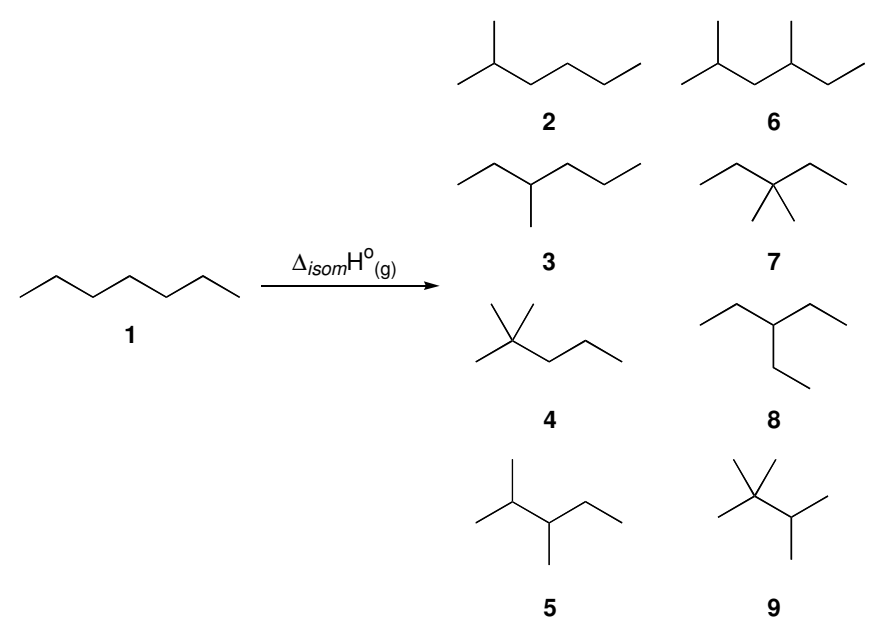

Figure 1: Structures of the heptane isomers. 


\section{Tables}

Table 1: Calculated $\Delta_{i s o m} \mathrm{H}_{(g)}^{\circ}$ errors for the isomerization of linear to branched heptanes using the B3LYP functional with various basis sets. Values are in $\mathrm{kcal} / \mathrm{mol}$ and presented as mean unsigned error [root mean squared error] (mean signed error).

\begin{tabular}{ll}
\hline basis set & \\
\hline STO-3G & $4.5[4.8](4.5)$ \\
$3-21+\mathrm{G}$ & $2.1[2.4](2.1)$ \\
$6-21 \mathrm{G}^{* *}$ & $4.0[4.3](4.0)$ \\
$4-31 \mathrm{G}^{* *}$ & $4.5[4.8](4.5)$ \\
$6-31++\mathrm{G}(\mathrm{d}, \mathrm{p})$ & $4.7[5.0](4.7)$ \\
$6-311++\mathrm{G}(\mathrm{d}, \mathrm{p})$ & $4.6[4.9](4.6)$ \\
D95++(d,p) & $4.4[4.7](4.4)$ \\
D95V++(d,p) & $4.5[4.7](4.5)$ \\
SHC* & $3.9[4.1](3.9)$ \\
CEP-4G* & $0.9[1.2](-0.6)$ \\
CEP-31G* & $3.6[3.8](3.6)$ \\
CEP-121G* & $4.4[4.6](4.4)$ \\
LanL2MB & $4.5[4.8](4.5)$ \\
LanL2DZ & $3.9[4.1](3.9)$ \\
SDDAll & $4.2[4.4](4.2)$ \\
aug-cc-pVDZ & $4.3[4.6](4.3)$ \\
aug-cc-pVTZ & $4.8[5.1](4.8)$ \\
SV & $4.6[4.9](4.6)$ \\
SVP & $4.9[5.2](4.9)$ \\
TZVP & $4.7[5.0](4.7)$ \\
QZVP & $4.3[4.5](4.3)$ \\
MIDI! & $2.3[2.5](2.3)$ \\
EPR-III & $4.9[5.2](4.9)$ \\
MTSmall & $4.9[5.2](4.9)$ \\
DGDZVP & $4.8[5.1](4.8)$ \\
DGDZVP2 & $4.2[4.5](4.2)$ \\
DGTZVP & $4.6[4.9](4.6)$ \\
CBSB7++ & $4.6[4.9](4.6)$ \\
\hline &
\end{tabular}


Table 2: Calculated $\Delta_{i s o m} \mathrm{H}_{(g)}^{\circ}$ errors for the isomerization of linear to branched heptanes using the CEP-4G*, 6-311++G(d,p), and aug-cc-pVDZ basis sets with various model chemistries. Values are in $\mathrm{kcal} / \mathrm{mol}$ and presented as mean unsigned error [root mean squared error] (mean signed error).

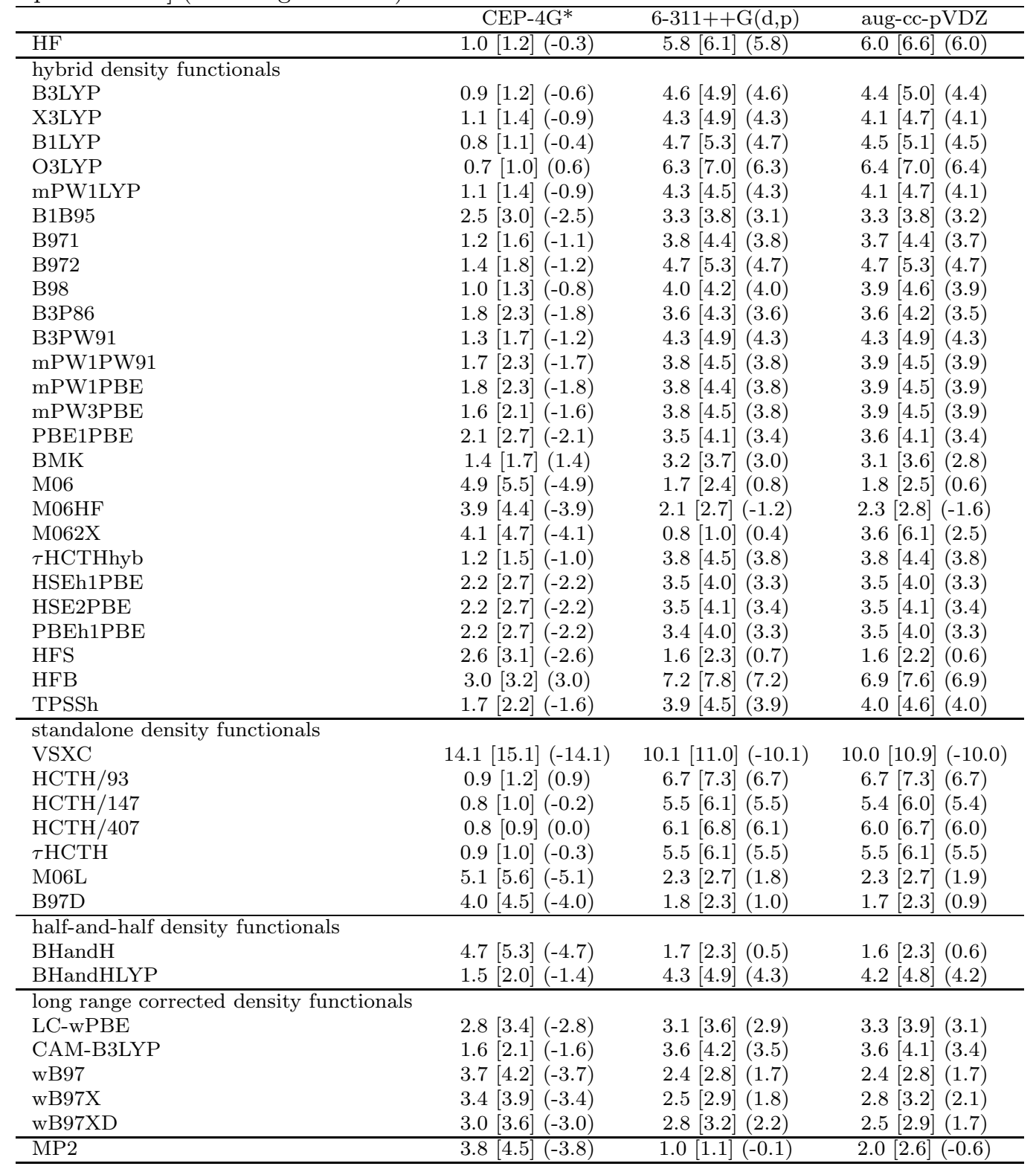


Table 3: Calculated $\Delta_{i s o m} \mathrm{H}_{(g)}^{\circ}$ errors for the isomerization of linear to branched heptanes using the major semiempirical and ab initio post-Hartree-Fock CBS-x and Gaussian-n composite methods. Values are in $\mathrm{kcal} / \mathrm{mol}$ and presented as mean unsigned error [root mean squared error] (mean signed error).

\begin{tabular}{ll}
\hline Semiempirical methods & $8.8[9.5](8.8)$ \\
AM1 & $3.9[4.2](3.9)$ \\
PM3 & $3.9[4.2](3.9)$ \\
PM3MM & $1.3[1.4](1.3)$ \\
PM6 & $1.1[1.4](1.1)$ \\
PDDG & $1.2[1.5](1.2)$ \\
\hline Complete Basis Set (CBS) methods & $0.9[1.3](0.9)$ \\
CBS-4M & \\
CBS-Q//B3 & $0.8[1.1](0.6)$ \\
\hline Gaussian-n methods & $0.8[1.1](0.7)$ \\
G1 & $0.8[1.1](0.7)$ \\
G2 & $0.9[1.2](0.8)$ \\
G2MP2 & $0.9[1.2](0.8)$ \\
G3 & $0.9[1.2](0.9)$ \\
G3MP2 & $0.8[1.2](0.8)$ \\
G3B3 & $0.8[1.2](0.8)$ \\
G3MP2B3 & $0.8[1.1](0.7)$ \\
G4 & \\
G4MP2 & \\
\hline
\end{tabular}

